\title{
Evaluation of Hyperimmune Hen Egg Yolk Derived Anti-Human Rotavirus Antibodies (Anti-HRVIgY) against Rotavirus Infection
}

\author{
Manika Buragohain ${ }^{1}$, Ganesh S. Dhale ${ }^{1}$, Govind R. Ghalsasi², Shobha D. Chitambar ${ }^{1}$ \\ ${ }^{1}$ Enteric Viruses Department, National Institute of Virology, Pune, India; ${ }^{2}$ SPF Eggs Division, Venky's (India) Ltd., Pune, India. \\ Email: drshobha.niv@gmail.com
}

Received September $10^{\text {th }}, 2011$; revised November $15^{\text {th }}, 2011$; accepted January $4^{\text {th }}, 2012$

\begin{abstract}
Oral delivery of specific IgY has been reported to be beneficial against rotavirus infection. However, the production of IgYs against globally prevalent human rotavirus (HRV) serotypes and their evaluation detailing the influence on the virological/histopathological consequences have not been reported to date. In the present study, anti-HRVIgY was generated in the eggs of specific pathogen free hens immunized with HRV serotypes G1 - G4 and G9 independently. Purified anti-HRVIgY preparations were tested to determine the ELISA and neutralizing antibody titers respectively in an indirect ELISA and cell culture based neutralization assay. Efficacy of pre and post infection treatment of antiHRV-3IgY was assessed in an infant BALB/c mouse model of human rotavirus infection by monitoring percent diarrhea, severity and duration of diarrhea, intestinal viral load and histopathology. High $(1: 64,000-1: 512,000)$ titered antiHRVIgYs were obtained from the egg yolk of immunized hens with peak titer value $(1: 256,000 / 1: 512,000)$ at $40-60$ day of immunization. In-vitro, each of the anti-HRVIgY preparations showed the presence of multiserotypic neutralizing activity with high $(1: 1600-\geq 1: 6400)$ homologous and low $(\leq 1: 50-1: 800)$ heterologous titers. However, anti-HRV3IgY neutralized all of the serotypes tested in the study indicating broader in-vitro neutralizing activity. In mice, post exposure treatment with anti-HRV-3IgY significantly reduced the extent of diarrhea and intestinal virus load and inhibited histopathological changes whereas pre exposure anti-HRV-3IgY treatment imparted immediate protection from development of rotavirus gastroenteritis. Thus, the anti-HRVIgY administered orally decreased morbidity and disease incidences in mice suggesting its potential implication in prophylactic and therapeutic usage in human to achieve reduction in rotavirus disease burden.
\end{abstract}

Keywords: IgY; Rotavirus; Mouse Model; Oral Immunotherapy

\section{Introduction}

Rotaviruses are the leading cause of acute infectious diarrhea in infants and young children, worldwide. These viruses account for half a million deaths annually in children $<5$ years of age, with majority (82\%) of the deaths occurring in developing countries [1]. In both developed and developing countries alike, rotavirus infections lead to an annual economic loss of several million US\$ in direct and indirect medical care [2-4]. Subsequent to the intussusception related withdrawal of the first rotavirus vaccine, different strategies, including both active and passive immunization/immunotherapy have been continuously attempted to develop a safe and effective intervention against rotavirus infection [5-7]. Two new generation rotavirus vaccines, RotaTeq and Rotarix have been introduced in the global market. In developed countries, the efficacy of these vaccines has been reported to be significant against rotavirus gastroenteritis of any severity $(74 \%-79 \%)$, severe rotavirus gastroenteritis $(90 \%$ - 98\%) and hospitalization due to rotavirus (96\%) [8]. As against this, in impoverished children from Asian and African countries, a low level $(39.3 \%-48.3 \%)$ of efficacy of rotavirus vaccine probably attributable to high concentration of transplacentally acquired maternal antibodies, interfering gut flora, diarrheal diseases caused by enteric infections other than rotavirus, micronutrient malnutrion and associated immunodeficiency and concomitant administration of oral poliovirus vaccine is described recently $[9,10]$. While inclusion of rotavirus vaccine in national childhood immunization program is under consideration in these settings [11], exploration of the alternate and adjunct strategies such as oral immunotherapy and antivirals carries valued significance for management of rotavirus infection.

Neutralizing antibodies (NAbs) generated against two 
outer capsid proteins, VP7 and VP4 of rotavirus have been described as correlates of protection from rotavirus disease [12-15]. These antibodies prevent infection locally by inhibiting rotavirus attachment to susceptible cells in the intestinal lumen $[16,17]$. As a corollary to this, oral delivery of rotavirus specific neutralizing milk, serum antibodies and monoclonal antibodies have been demonstrated to impart local passive protection against rotavirus infection [18]. However, the practical application of these antibodies as oral immunotherapy may be limited because of difficulties in large-scale production.

In recent years, a considerable attention has been drawn towards chicken eggs as a good source of conveniently packaged antibodies useful for immunotherapeutics and diagnostics. Chicken produces a unique immunoglobulin molecule called $\operatorname{IgY}$ that is functionally homologous to mammalian IgG [19]. IgY, the serum antibodies of chicken are passed from hens to embryo via the egg yolk. Laying hens immunized against different antigens, transport high concentration of specific IgY to the egg yolk. Nonreactivity of IgY with mammalian Fc receptors, an evolutionarily distinctive biochemical property makes IgY antibodies appropriate for per oral immunotherapy [20].

The beneficial effect of purified IgY antibodies specifically generated against rotaviruses has previously been described [21-23]. However, such studies have rarely included the production and evaluation of IgYs against globally prevalent rotavirus serotypes, G1 - G4 and G9, essentially required for practicability of the approach. Further, the effect of orally supplied rotavirus specific IgY antibodies on the intestinal viral load and cellular pathological changes has not been examined. The objective of the present study was to produce $\operatorname{IgY}$ antibodies against common rotavirus types and evaluate their neutralizing activity against homotypic and heterotypic rotavirus infections in-vitro and also to test the homotypic protective efficacy of $\operatorname{IgY}$ antibodies in a murine model of human rotavirus (HRV) infection of G3 origin.

\section{Materials and Methods}

\subsection{Viruses and Cells}

The human (HRV-1, KU/G1P [8]; HRV-2, S2/G2P [4]; HRV-3, YO/G3P [8]; HRV-4, ST-3/G4P [6] and HRV-9, F-45/G9P [8]) and simian (SA-11/G3P [2]) rotavirus serotypes were procured from Sapporo Medical College, Sapporo, Japan. The fetal monkey kidney derived cell line, MA104 used in the study was obtained from National Center for Cell Science, Pune, India. The viruses were activated with trypsin (Sigma, USA) $(4 \mu \mathrm{g} / \mathrm{ml})$ at $37^{\circ} \mathrm{C}$ for half an hour (h) and adsorbed on the monolay- ers of MA104 cells with $80 \%$ cell density at $37^{\circ} \mathrm{C}$ for 90 min. The cells were refed with serum free Minimum Essential Medium Eagle (MEM, Himedia, India) containing $1 \mu \mathrm{g} / \mathrm{ml}$ trypsin and incubated at $37^{\circ} \mathrm{C}$ until the occurrence of $4+(100 \%$ detachment of cells $)$ cytopathic effect. ELISA End Point (EEP) titers of the stocks were determined by an antigen capture ELISA [24] and infectivity assay comprised of cell culture and ELISA [25]. A single virus stock produced for each of the rotavirus serotypes was utilized for the entire study.

\subsection{Purification of Viruses}

All of the rotavirus serotypes propagated in MA104 cell line were purified by rate zonal ultracentrifugation (Sorvall Ultracentrifuge OTD-COMBI, USA) using 20\% $60 \%$ continuous sucrose gradient as described earlier [26] with minor modifications in the protocol. Antigen capture ELISA was performed on the fractions collected from a gradient column. The fractions were pooled according to the $\mathrm{OD}_{450}$ values and centrifuged at $30,000 \mathrm{rpm}$ for $2 \mathrm{~h}$ to pellet the virus and remove the sucrose. The pelleted virus was reconstituted in $0.01 \mathrm{M}$ phosphate buffered saline (PBS), pH 7.4 and viral protein was determined [27].

\subsection{Immunization of Birds and Collection of Eggs}

Eighteen week old seronegative single comb White Leghorn pullets (SPF Division, Venky's India Ltd) reared in specific pathogen free (SPF) facility at Poultry Diagnostic and Research Center, Venky's India Ltd. Pune were utilized for antibody production. Five groups of birds with seven birds per group were immunized separately with HRV serotypes $1-4$ and 9. A group of fifteen unimmunized age matched birds served as control group. Hundred microgram of viral protein suspended in $0.5 \mathrm{ml}$ of $0.01 \mathrm{M} \mathrm{PBS}, \mathrm{pH} 7.4$ was mixed with equal volume of Freund's complete adjuvant (Sigma, USA) and inoculated per bird in breast muscles and ventral aspects of wings via intramuscular $(\mathrm{i} / \mathrm{m})$ and subcutaneous $(\mathrm{s} / \mathrm{c})$ routes respectively. The birds received the first booster after two week interval followed by two booster doses at weekly interval with Freund's incomplete adjuvant (Sigma, USA). The last booster $(50 \mu \mathrm{g}$ viral protein) was administered intravenously (i/v) without adjuvant. Bleeding was performed after every dose of immunization and serum samples were tested for the presence of anti-rotavirus antibodies by ELISA. Both control and experimental birds started egg laying at the age of 21 week, the period following $3^{\text {rd }}$ dose of immunization. Eggs were collected on daily basis up to 6 to 8 weeks after the inoculation of last booster dose and 
stored at $+4^{\circ} \mathrm{C}$ until used.

\subsection{Purification of IgY from Immune Eggs}

Eggs laid by the immunized hens were pooled (30 - 35 eggs per pool) on weekly basis. The yolks were separated from egg white and washed with chilled 0.01 M PBS, $\mathrm{pH}$ 7.4 to remove traces of albumin and dried completely on filter paper. One hundred $\mathrm{ml}$ of yolk was further processed for purification of IgY using polyethylene glycol (PEG 8000) and ammonium sulfate (Sigma, USA) as described earlier [28]. Purified IgY was dialyzed four times against $0.01 \mathrm{M}$ PBS, $\mathrm{pH} 7.4$ to remove the residues of salt. After estimation of protein content, IgY was stored at $-20^{\circ} \mathrm{C}$ until used.

\subsection{Detection and Titration of Anti-HRVIgY Antibodies in Serum and Egg Yolk}

The presence of anti-HRVIgY antibodies in serum and egg yolk of immunized hens was monitored and assayed by modified protocol of an indirect ELISA described earlier [29]. Briefly, purified simian rotavirus strain, SA11 (as group reactive antigen) coated on microtiter plates (Immunol-H, Dynatech USA) was allowed to react with serum and yolk samples diluted serially at two folds in $0.01 \mathrm{M}$ PBS, pH 7.4 containing $2.5 \%$ skimmed milk powder and $0.05 \%$ Tween-20. Bound anti-HRVIgYs were probed by rabbit anti-chick IgG conjugated to horse raddish peroxidase enzyme (Bangalore Genei, India) at 1:20,000 dilution followed by its reaction with Tetramethylbenzedine substrate (Bangalore Genei, India). The cut off value was set as mean $\mathrm{OD}_{450}$ of serum and $\operatorname{IgY}$ samples from control birds +3 standard deviation.

\subsection{Cell Culture Based In-Vitro Neutralization Assay}

In-vitro neutralization potency of anti-HRVIgYs was tested in MA104 cell monolayers combined with a rotavirus antigen capture ELISA [30]. Briefly, 100 EEP of each of the HRV serotypes was incubated with two fold serially diluted corresponding $\operatorname{IgY}$ samples at $37^{\circ} \mathrm{C}$ for $0.5 \mathrm{~h}$. The mixture was allowed to adsorb on MA104 cell monolayers grown in microplates (Nunc, USA). After 18 $\mathrm{h}$ of incubation at $37^{\circ} \mathrm{C}$ in a humidified $5 \% \mathrm{CO}_{2}$ atmosphere, the plates were frozen at $-70^{\circ} \mathrm{C}$ and a rotavirus antigen detection ELISA was carried out on the culture harvests from the wells. The percent neutralization of virus was calculated as $100-\{[(\mathrm{Diln}-\mathrm{C} 1) /(\mathrm{C} 2-\mathrm{C} 1)] \times$ 100 \} wherein $\mathrm{C} 1$ :OD of control well, $\mathrm{C} 2$ :OD of virus dilution used in the test, Diln:OD of IgY dilution [31]. The reciprocal of the highest dilution of an IgY preparation indicating $\geq 50 \%$ neutralization was considered as titer of NAbs. Each type of anti-HRVIgY was tested for its neutralizing activity against all five serotypes used in the study.

\subsection{Anti-HRVIgY Treatment of Mice Infected with Rotavirus}

All animal experiments were approved by Institutional Biosafety Committee and Institutional Animal Ethical Committee of National Institute of Virology, Pune India. A previously characterized infant BALB/c mouse model of human rotavirus infection [32] was used to evaluate pre and post exposure treatment efficacy of anti-HRVIgY.

The infections were induced orally in 4/5 day old mice using 4000 EEP of HRV-3 (strain YO), a dose that proved to cause $100 \%$ attack rate manifesting diarrhea and intestinal histopathological changes in the inoculated mice [32]. Post exposure treatment was commenced at 12 hour post inoculation (hpi) via oral route with $50 \mu$ lantiHRV-3IgY per animal that continued as twice daily till day 3 post inoculation. Three different doses $1.25,0.625$, $0.3125 \mathrm{mg} / \mathrm{ml}$ of anti-HRV-3IgY were tested respectively in $n=21,21$ and 20 mice. Two groups of mice, 1) inoculated with HRV-3 but not treated with $\operatorname{IgY}(\mathrm{n}=23)$ and 2) HRV-3 uninoculated and IgY untreated $(\mathrm{n}=16)$ were included as controls. The animals were examined daily for the signs of diarrhea during the experimental period of $120 \mathrm{hpi}$ and the outcome was measured as prevalence of diarrhea (defined as the percentage of pups with diarrhea on a daily basis), severity (defined as the sum of diarrhea scores of each pup during the course of experiment) and duration of diarrhea (defined as time in days with diarrhea) [6,33]. At the end of the course of treatment (96 hpi), six pups from each group including those from the control groups were necropsied and the tissue samples from lower intestine were processed for quantification of viral load and pathological analysis.

For pre exposure treatment, 19 and 20 animals/group were fed respectively with $50 \mu 1$ of 250 and $125 \mu \mathrm{g} / \mathrm{ml}$ of anti-HRV-3IgY per mouse $2 \mathrm{~h}$ prior to oral challenge with 2000 EEP of HRV-3. Two groups of animals, one infected with HRV-3 but not treated with anti-HRV-3IgY $(\mathrm{n}=18)$ and the other without inoculation or treatment ( $\mathrm{n}$ $=10$ ) served as controls. The occurrence of diarrhea in the animals was recorded during the experimental period. Real time PCR and histopathological analyses were carried out on the intestinal tissues collected from experimental and control groups at 72 hpi.

\subsection{Real Time PCR}

The mouse stool and intestinal tissue samples were ex- 
tracted with TRIzol ${ }^{\circledR}$ LS and TRIzol ${ }^{\circledR}$ respectively (Invitrogen Life Technologies, USA) as per the manufacturer's protocol for isolation of rotavirus RNA. Complementary DNA (cDNA) was prepared from $10 \mu \mathrm{l}$ RA by reverse transcription using M-MuLV reverse transcriptase (Roche, USA) in the presence of VP6 gene specific primers-VP6F-5'GACGGVGCRACTACATGGT3' and VP6R-5'GTCCAATTCATNCCTGGTG3' (where R $=\mathrm{A}$ or $\mathrm{G} ; \mathrm{V}=\mathrm{A}, \mathrm{C}$ or $\mathrm{G} ; \mathrm{N}=\mathrm{A}, \mathrm{T}, \mathrm{C}$ or $\mathrm{G})$. The resulting cDNA was used as template for real time PCR. Quantitect SYBR green PCR mastermix kit (Qiagen, USA) was used for real time PCR quantification of rotavirus VP6 RNA as described earlier [34]. Eight serial dilutions of the plasmid containing $10^{8}$ to $10^{1}$ copies of rotavirus VP6 gene fragment were included in each reaction to serve as positive controls to construct the standard curve and quantitate the rotavirus in the experimental specimens. The optimal viral load cut off values that can be associated with infectious intestinal disease and clearance of the virus from intestine of the infected mice was set as per criterion described earlier [35,36].

\subsection{Pathology}

The intestinal tissue segments were inflated with $10 \%$ neutral buffered formalin, treated with ascending and descending grade of alcohol and embedded in paraffin to prepare sections of $3-5 \mu \mathrm{m}$ thickness and stain with haematoxylin and eosin by standard procedure [37]. Tissue sections from mice treated with different doses of IgY were analyzed for histopathological changes associated with rotavirus infection.

\subsection{Statistics}

Comparison of IgY treated versus untreated mice for the occurrence diarrhea in day wise manner was done by Fisher's exact test [38]. Severity of infection and duration of diarrhea were analyzed by Kruskal-Wallis test [39]. Differences in the intestinal viral load as monitored by real-time PCR were assessed using Mann-Whitney test [40].

\section{Results}

\subsection{Virus Stocks}

ELISA and infectivity assay performed on different stocks of rotavirus serotypes monitored EEP titer values respectively of $1: 64$ and1:1280 for HRV-1; $1: 128$ and $1: 800$ for HRV-2, 1:256 and1:800 for HRV-3; 1:128 and 1:1280 for HRV-4; $1: 64$ and 1:1280 for HRV-9 and 1:512 and 1:2560 for SA-11. Purification of the viruses by ultracentrifugation on a continuous sucrose gradient $(20 \%-60 \%)$ yielded sedimentation of the viruses at $30 \%$
- $40 \%$ in a column, with fractions containing ELISA S/N (Sample $\mathrm{OD}_{450} /$ Mean negative control $\mathrm{OD}_{450}$ ) ratios between 11.34 and 12.37. Protein concentrations of the purified virus stocks varied from 0.28 to $0.47 \mathrm{mg} / \mathrm{ml}$.

\subsection{Anti-HRVIgY Responses in Serum and Yolk of Immunized Hens}

None of the hens showed any clinical signs of distress in response to the immunization against rotaviruses. Average egg laying rate (5 eggs/hen/week) of the hens immunized with rotavirus was not affected as compared to that of the control hens.

The profiles of anti-HRVIgY antibodies in serum and egg yolk of the immunized hens as monitored by indirect ELISA are depicted in Figure 1. Anti-HRVIgY titers in the serum increased rapidly after $2^{\text {nd }}$ dose of immunization with peaked Geometric Mean Titer (GMT) value at 1:144915.8 against HRV-1; $1: 131253.7$ against HRV-2; 1:231865.3 against HRV-3; and 1:256000 against HRV-4 after $4^{\text {th }}$ dose (at 35 days of $1^{\text {st }}$ immunization) and remained at plateau after the $5^{\text {th }}$ dose except in the group immunized with HRV-9. The latter group attained a highest GMT of 1:90509.67 after $5^{\text {th }}$ dose.

Eight to nine lots of anti-HRVIgY prepared against each of the HRV serotypes were obtained from the eggs collected during the experimental period of 11 - 12 weeks. Different anti-HRVIgY preparations showed 1:64,000 to 1:512,000 ELISA antibody titers with a peak value of $1: 256,000 / 1: 512,000$ at $40-60$ day after $1^{\text {st }}$ dose of immunization (Figure 1). The protein concentrations of these preparations varied from 2.8 to $3.7 \mathrm{mg} / \mathrm{ml}$. The IgY prepared from the eggs of unimmunized control hens showed the presence of $2.3 \mathrm{mg} / \mathrm{ml}$ of protein, however, absence of rotavirus specific antibodies.

\subsection{Homotypic and Heterotypic Neutralizing Activity of Anti-HRVIgYs}

The highest homotypic/heterotypic neutralizing activity of the anti-HRVIgY preparations corresponded with their peak ELISA titers. The titers were high $(1: 1600$ to $\geq$ 1:6400) against homotypic strains and low/negligible $(\leq 1: 50$ to $1: 800)$ against heterotypic strains (Table 1). AntiHRV-3IgY preparation was found to possess broader neutralizing activity with the ability to neutralize all of the serotypes tested in the study. On the other hand antiHRV-4IgY showed a narrow spectrum of neutralization with heterotypic neutralizing antibodies against HRV-3 and HRV-9 only. AntiHRV-1, 2 and 9IgY preparations neutralized the serotypes other than HRV-4. The control IgY preparation obtained from unimmunized hens was tested negative for neutralizing antibodies. 

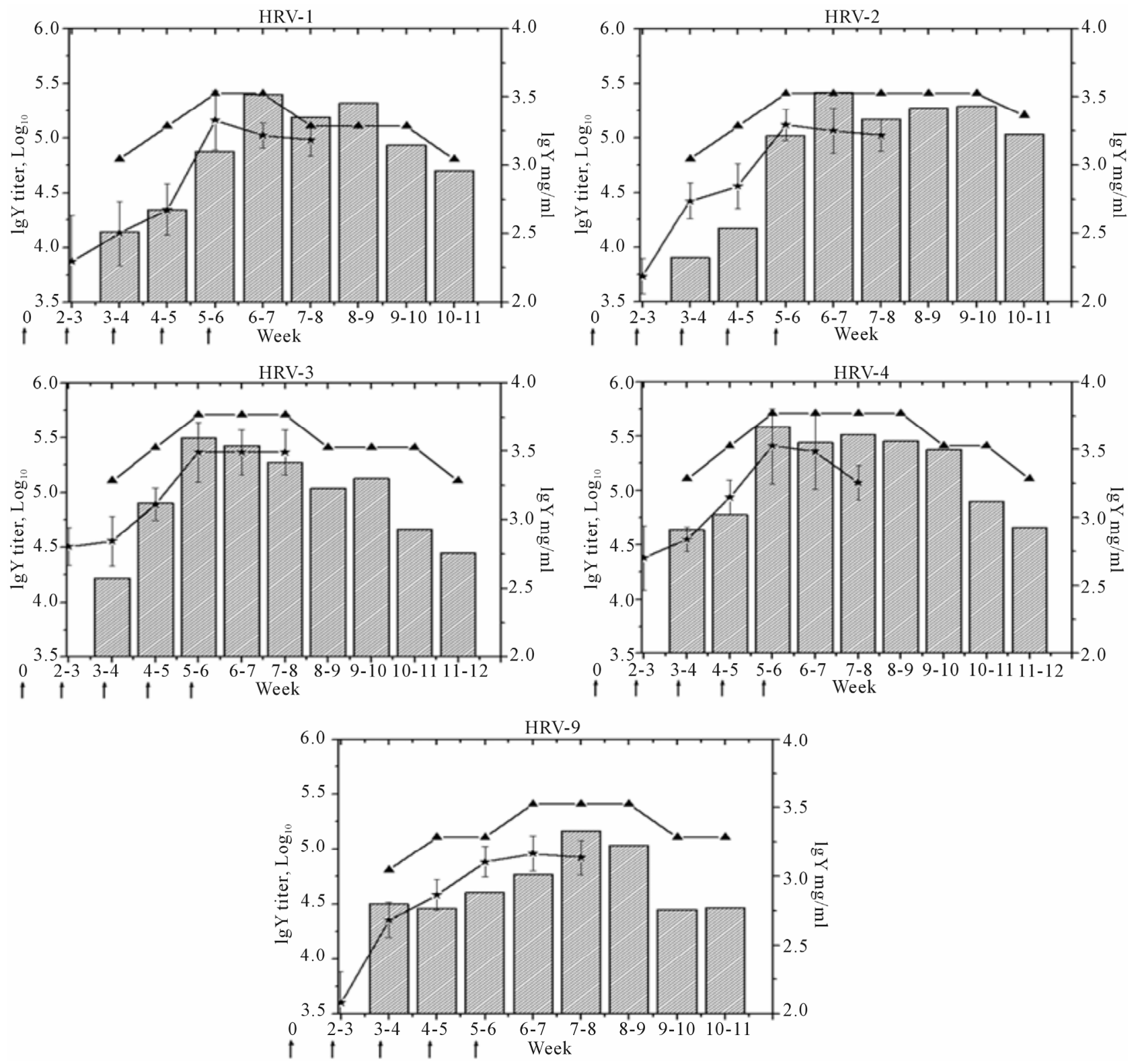

Figure 1. Anti-HRVIgY titers in serum $(\star)$ ) and egg yolk $(\neg)$ of hens immunized against different human rotaviruses. The bars ( indicate protein content of the IgY preparations. The arrows denote time points of immunization doses.

Table 1. Neutralizing antibody titers in IgY preparations obtained from egg yolk of hens immunized with different HRV serotypes.

\begin{tabular}{lccccc}
\hline \multirow{2}{*}{ IgY Abs } & \multicolumn{5}{c}{ NAb titers against HRV serotypes } \\
\cline { 2 - 6 } & HRV-1 & HRV-2 & HRV-3 & HRV-4 & HRV-9 \\
\hline HRV-1IgY & $1: 1600$ to $\geq 1: 6400$ & $1: 50$ to $1: 100$ & $1: 200$ to $1: 400$ & $<1: 50^{\text {a }}$ & $1: 200$ to $1: 400$ \\
HRV-2IgY & $1: 50$ to $1: 100$ & $1: 1600$ to $1: \geq 6400$ & $1: 100$ to $1: 200$ & $<1: 50^{\text {a }}$ & $1: 50$ to $1: 100$ \\
HRV-3IgY & $1: 200$ to $1: 400$ & $1: 50$ to $1: 200$ & $1: 1600$ to $\geq 1: 6400$ & $1: 400$ to $1: 800$ & $1: 100$ to $1: 400$ \\
HRV-4IgY & $<1: 50^{\text {a }}$ & $<1: 50^{\text {a }}$ & $1: 400$ to $1: 800$ & $1: 3200$ to $1: \geq 6400$ & $1: 50$ to $1: 100$ \\
HRV-9IgY & $1: 200$ to $1: 400$ & $1: 50$ to $1: 100$ & $1: 100$ to $1: 400$ & $<1: 50^{\text {a }}$ & $1: 3200$ to $1: \geq 6400$ \\
\hline
\end{tabular}

${ }^{a}$ titer $<1: 50$ was considered as insignificant. 


\subsection{Effect of Post Infection Administration of Anti-HRVIgY on the Course of Rotavirus Infection in Mice}

\section{1) Diarrhea}

Oral inoculation of 1:4000 EEP of YO strain of HRV3 in 4/5 day old BALB/c mice typically induced diarrhea at $24 \mathrm{hpi}$ with a disease peak at day 2 to 3 . Administration of anti-HRV-3IgY in these mice produced a clear dose dependent positive effect on reduction of percentage of diarrhea and severity and duration of disease (Figure 2(A), Table 2). Feeding of the animals twice daily with $50 \mu \mathrm{l}$ of $1.25 \mathrm{mg} / \mathrm{ml}$ of anti-HRV-3IgY resulted in the decrease of diarrhea by $58 \%$ on day 2 and $81 \%$ on day 3 as compared to the percent diarrhea noted in infected but untreated mice $(p<0.001$ for day 2 and $p<0.0001$ for day 3). The beneficial effect was also pronounced in pups receiving $50 \mu \mathrm{l}$ of $0.625 \mathrm{mg} / \mathrm{ml}$ of anti-HRV-3IgY with $53 \%$ and $62 \%$ reduction in diarrhea on day 2 and 3 respectively as against the untreated group $(\mathrm{p}<0.001$ for both). The lower dose, $0.3125 \mathrm{mg} / \mathrm{ml}$ imparted low but significant $(\mathrm{p}<0.05)$ protection by reducing diarrhea by $26 \%$ on day 2 and $35 \%$ on day 3 as compared to untreated control group. IgY antibody treatment also shortened the diarrhea duration by 0.78 to 1.36 days and alleviated severity by $23.19 \%$ to $48.45 \%$ as compared to that noted in the untreated group of mice (Table 2).

2) Rotaviral RNA load in the intestine and stool

At the end of the course of anti-HRV-3IgY treatment, the group of mice treated with $1.25 \mathrm{mg} / \mathrm{ml}$ cleared $(\mathrm{GMCt} \geq 30,31.88)$ the virus from intestine while in the groups treated with 0.625 and $0.3125 \mathrm{mg} / \mathrm{ml}$, reduction in the intestinal virus (respectively GMCt 27.87 and 25.62) $(\mathrm{p}<0.01 / \mathrm{p}<0.05)$ was well below the level (GMCt 24) that could produce infectious intestinal disease (Figure 2(B)). On the other hand, the viral load in the intestines of infected but untreated mice was higher (GMCt 20.2) than all of the $\operatorname{IgY}$ treated groups.

Treatment with anti-HRV-3IgY also resulted in diminished shedding of rotaviral RNA in the diarrheic stool by $8.8 \%-21.4 \%$ on day 2 (GMCt of 23.2, 21.2 and
20.0 respectively in $1.25 \mathrm{mg} / \mathrm{ml}, 0.3125 \mathrm{mg} / \mathrm{ml}$ and 0.625 $\mathrm{mg} / \mathrm{ml}$ IgY treated animals) and $14.6 \%-28.0 \%$ on day 3 (GMCt of 25.9, 24.1 and 21.9 respectively in $1.25 \mathrm{mg} / \mathrm{ml}$, $0.625 \mathrm{mg} / \mathrm{ml}$ and $0.3125 \mathrm{mg} / \mathrm{ml} \mathrm{IgY} \mathrm{treated} \mathrm{groups)} \mathrm{as}$ compared to infected but untreated control group (GMCt of 18.2 and 18.7 on day 2 and 3 respectively) $(\mathrm{p}<0.05)$.

3) Histopathology of intestine

Formalin fixed intestinal tissue sections from mice treated with different doses of anti-HRV-3IgY were analyzed for the major histopathological changes described to be associated with human rotavirus infection $[32,41]$. The intestinal sections of HRV-3 infected mice untreated with IgY presented typical histopathology with vacuolization in enterocytes at the distal one third of villi and blunting of villi at 96 hpi. The tips of the infected villi were unstainable due to epithelial cell death. On the other hand, the intestinal sections from the groups of mice treated with different doses of IgY showed reduced vacuolization and cell death at villus tips at 96 hpi (Figure 2(C)). Treatment with $1.25 \mathrm{mg} / \mathrm{ml}$ of IgY prevented marked visible lesions while the lower doses allowed minimal to mild vacuolization in the villi epithelium of intestine. The uninfected negative control mice showed a normal histology.

\subsection{Effect of Preinfection Feeding of Anti-HRVIgY in Mice}

Preinfection anti-HRV-3IgY treatment of the mouse pups provided $95 \%-100 \%$ protection from diarrhea in a dose dependent manner. Almost all animals were free from the signs of diarrhea on day 2 and day 3 , the time points that mark peak clinical disease (Figure 3(A)). Only 1/20 animals from the group treated with $125 \mu \mathrm{g} / \mathrm{ml}$ of antiHRV-3IgY developed mild diarrhea on day 1 which subsided on day 2 of HRV inoculation. The rotaviral RNA in the intestines was undetectable at $72 \mathrm{hpi}$ as per the set criterion (GMCt $\geq 30$ for RNA $<10$ copies) in both, 250 $\mu \mathrm{g} / \mathrm{ml}(\mathrm{GMCt} 31.81)$ and $125 \mu \mathrm{g} / \mathrm{ml}$ (GMCt 30.52) IgY treated groups (Figure 3(B)). Histologically, the lower intestines appeared normal and comparable to that of

Table 2. Duration and severity of diarrhea in different groups of mice treated with anti-HRV-3IgY.

\begin{tabular}{|c|c|c|c|}
\hline Group & $\begin{array}{l}\text { No. of mice with diarrhea (\%) } \\
\text { No of mice inoculated with HRV-3 }\end{array}$ & $\begin{array}{c}\text { Duration of diarrhea in days } \\
\text { Mean } \pm \text { SE }\end{array}$ & $\begin{array}{c}\text { Severity score } \\
\text { Mean } \pm \text { SE }\end{array}$ \\
\hline $\begin{array}{c}\text { Untreated } \\
\text { With antiHRV-3IgY }\end{array}$ & $23 / 23(100 \%)$ & $2.78 \pm 0.67$ & $3.88 \pm 0.74$ \\
\hline $\begin{array}{c}\text { Treated } \\
\text { with antiHRV-3IgY } \\
1.25 \mathrm{mg} / \mathrm{ml}\end{array}$ & $7 / 21(33 \%)$ & $1.42 \pm 0.53^{* *}$ & $2.00 \pm 0.47 * *$ \\
\hline $0.625 \mathrm{mg} / \mathrm{ml}$ & $11 / 21(52 \%)$ & $1.75 \pm 0.67 *$ & $2.62 \pm 0.46^{*}$ \\
\hline $0.3125 \mathrm{mg} / \mathrm{ml}$ & $17 / 20(85 \%)$ & $2.00 \pm 0.84 *$ & $2.98 \pm 0.57 *$ \\
\hline
\end{tabular}

${ }^{*} \mathrm{p}<0.05, * * \mathrm{p}<0.01$ vs untreated group (Kruskal-wallis test). 


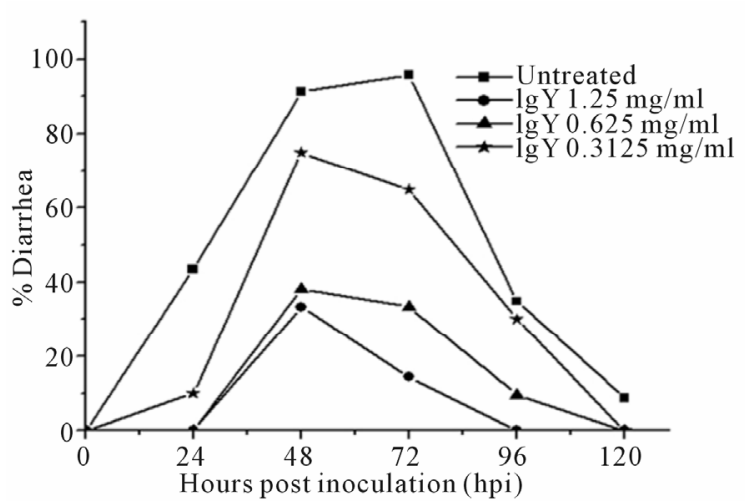

(A)

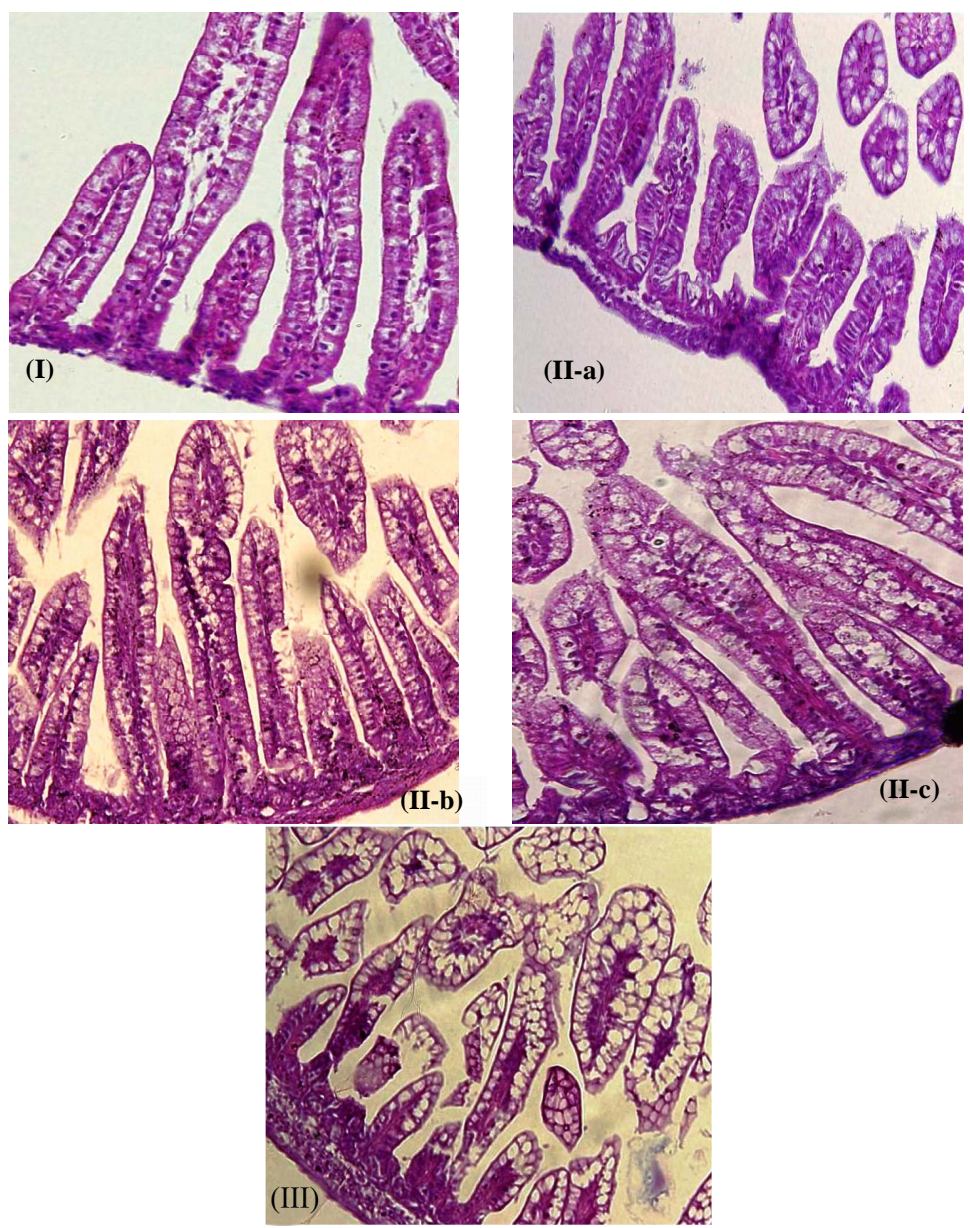

(C)

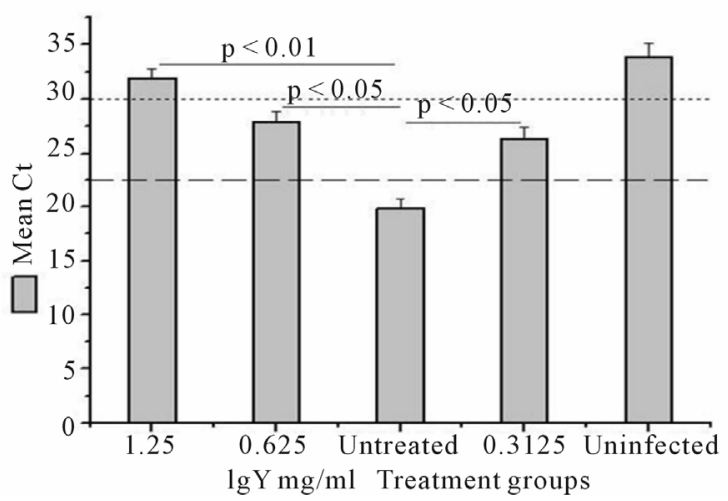

(B) 


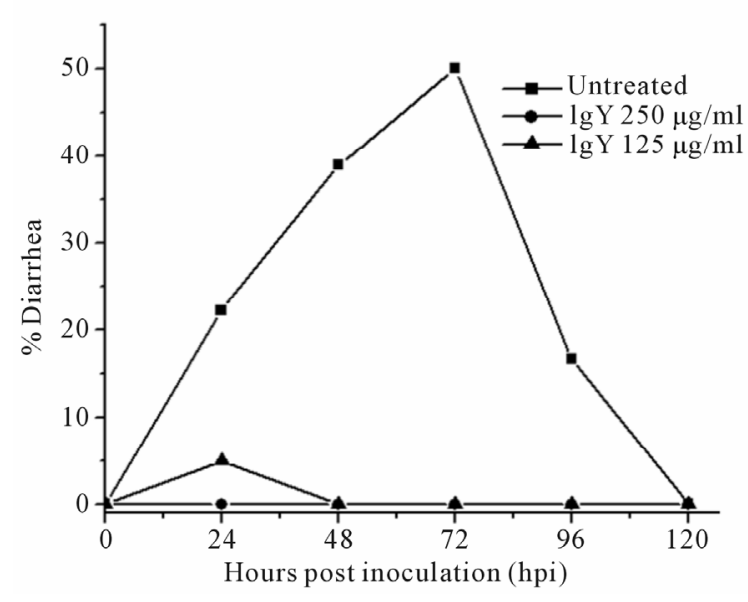

(A)

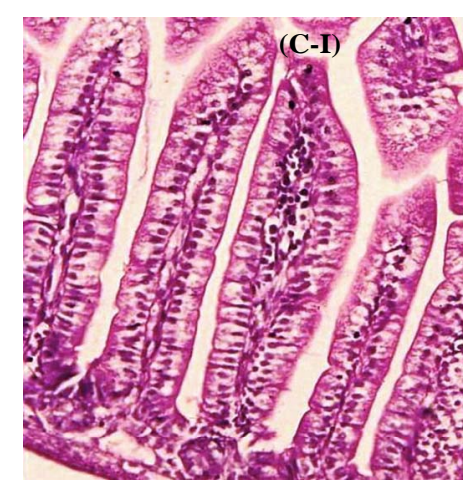

(C)

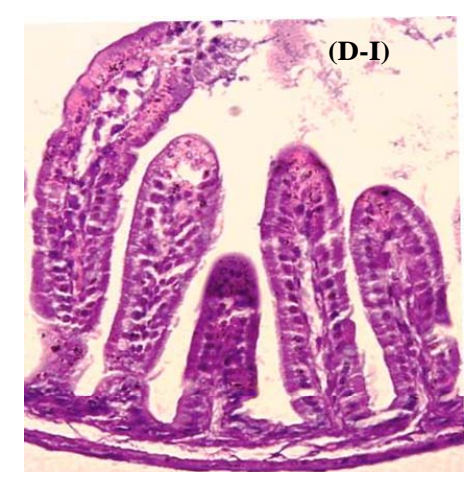

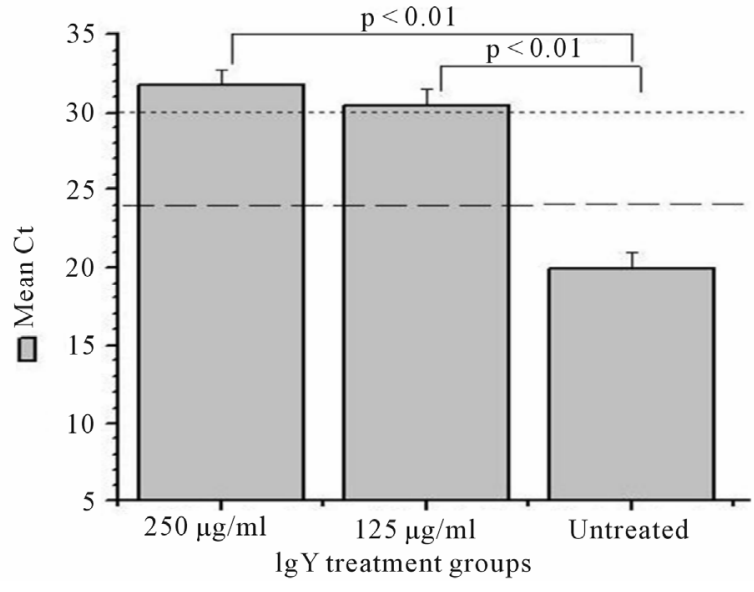

(B)
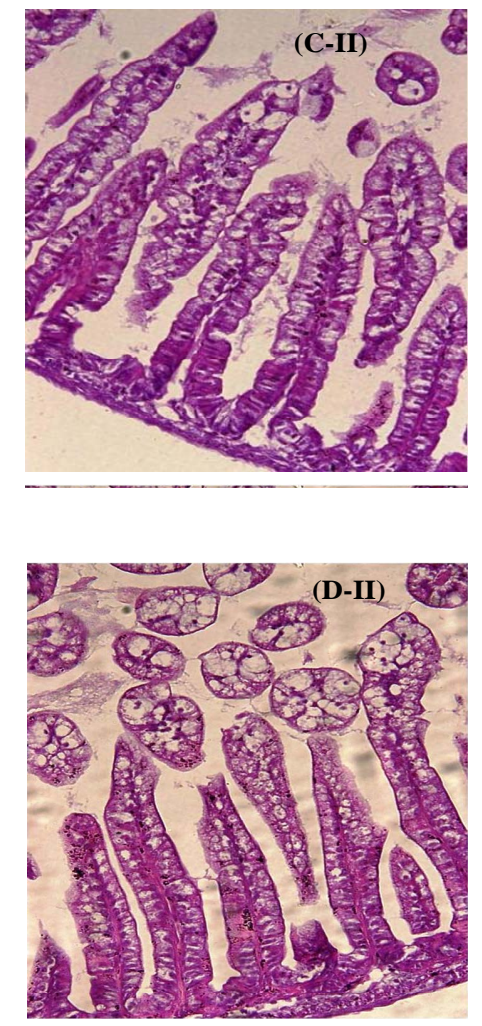

(D)

Figure 3. Effect of pre HRV-3 infection treatment with anti-HRV-3IgY. (A) Percent diarrhea in mice following IgY treatment; (B) Rotavirus RNA load in the intestines of mice at 72 hpi (each bar represents mean Ct value for six animals); (C) Intestinal histology in $250 \mu \mathrm{g} / \mathrm{ml}$ (C-I) and $125 \mu \mathrm{g} / \mathrm{ml}$ (C-II) IgY treated mice (displaying absence of pathological lesions) (H\&E, 20×); (D) Tissue sections of intestine from uninfected control mouse (D-I) and infected but IgY untreated mouse (D-II) presenting with rotavirus infection associated lesions (H\&E, 20×).

uninfected healthy control mice (Figures 3(C) and (D-I)). HRV inoculation developed diarrhea in 39\% (7/18) and $50 \%(9 / 18)$ of IgY untreated animals at day 2 and 3 respectively (Figure 3(A)), with an overall diarrhea prevalence of $55 \%$, mean severity score 2.7 and duration 2.2 days over the experimental period of $120 \mathrm{hpi}$. The intestinal tissue sections collected at 72 hpi showed the accumulation of rotavirus RNA (GMCt 19.9) and presence of histological lesions specific to rotavirus infection (Figures 3(B) and (D-II)). 


\section{Discussion}

Development of an effective oral immunotherapy necessitates generation of larger quantities of high titered, good quality pathogen specific antibodies and their extensive evaluation. Since, a single hen can produce up to 30 gm of purified IgY per year with $2 \%$ - $10 \%$ specific antibodies, egg yolk have potential of providing larger and more economical supply of specific antibody than any other sources [42]. The present study describes the preparation of human rotavirus specific egg yolk derived immunoglobulin, anti-HRVIgY and its evaluation for oral immunotherapy in a mouse model of human rotavirus infection.

Production of specific IgY is known to be achieved by immunizing laying hens with target antigen. However, five major factors such as the antigen (dose and molecular weight), type of adjuvant used, route and frequency of immunization and interval between immunizing doses influence the generation of specific immune response in hens [43]. Rotaviruses are known to be good immunogen while Freund's adjuvants remain the most effective ones among more than 100 known adjuvants [44,45]. The amount of rotavirus antigen mixed in Freund's adjuvants and route and schedule of immunization employed in the present study efficiently induced a high titered and long lasting anti-rotavirus IgY antibody response in eggs of immunized hens without any marked effect on rate of egg lay and size of egg known to govern efficient production and yield of egg antibodies [46]. The specific antibodies appeared in blood (serum) of pullets as early as two weeks after the primary dose of immunization with rotavirus, steadily increased following booster doses and remained static. The pullets started laying after the $3^{\text {rd }}$ dose of immunization. At this time point, the high titers of anti-rotavirus antibody present in the serum (Figure 1) facilitated the transfer and accumulation of high amount of anti-rotavirus antibody in the egg yolk. The titers persisted at elevated levels in the IgY prepared against all five types of human rotavirus throughout the experimental period (11 - 12 weeks). This finding is in accordance with previous observations that described high specific immune responses in the egg yolk from hens immunized with bovine rotavirus serotype 6 and 10 , HRV serotype 3 (strain MO) and other enteric pathogens [22,47-49].

Neutralization of virus infectivity by antibodies is an important arm of immunity to fight against viral infection. Usually level of protection correlates with the in vitro neutralization titers [50]. It has been reported that the variable epitopes, immunodominant in nature and the conserved epitopes, immunorecessive in nature on the VP7 and VP4 capsid proteins across the serotypes of rotavirus respectively elicit homotypic and heterotypic neutralizing antibodies [51-53]. Each of the anti-HRVIgY preparations obtained in the present study was able to neutralize two or more serotypes of rotavirus apart from the serotype involved in its own production. The multiserotypic neutralization response probably developed slowly and was independent of doses used for immunization as described earlier [54].

The mouse model of human rotavirus YO infection used in the study has been reported to have a course of infection of 5 days with highest rate of virus replication within 24 hpi [32]. Hence, the post exposure treatment of the infected animals with homologous (anti-HRV-3IgY) polyclonal antibodies in the present study was initiated at 12 hpi. Further the protection achieved by passive oral immunotherapy against enteric infections is known to reflect solely the effect of externally delivered immunoglobulins. The immunoglobulin with high content of neutralizing activity is expected at the mucosal site to control the infection process [23]. In the present study, the dose of IgY for in vivo testing was decided predominantly on the basis of neutralizing antibody titer determined in the in vitro assay followed by its protein concentration. The 12 hourly regimen of post infection treatment with anti-HRV-3IgY antibodies successfully blunted the disease by reducing viral load, normalizing pathological features and mitigating diarrhea in the mouse model used in the present study. The higher doses produced a stronger effect corroborating the dose dependent response of oral immunoglobulin treatment observed earlier against various enteric diseases in different animal models $[23,36]$.

Since most of the naturally occurring rotavirus infections are caused by low doses of virus [55], the mice treated with IgY prior to infection were challenged with a low dose of HRV-3 that was found to cause diarrhea in $55 \%$ of the animals. The animals did not develop diarrhea and were devoid of rotaviral RNA and pathological lesions in the intestines at 72 hpi (Figure 3) as reported earlier [21].

It is to be noted that though in-vitro neutralization of five major HRV serotypes in cell culture as well as invivo protection against HRV-3 induced gastroenteritis in mice could be monitored efficiently by anti-HRV-3IgY treatment, the in-vivo protective efficacy of the same preparation (anti-HRV-3IgY) against HRV serotypes 1, 2, 4 and 9 could not be assessed in the present study due to the absence of a mouse model of gastroenteritis for these serotypes. The HRV serotypes other than 3 have been reported to replicate inefficiently to produce diarrhea in mice [56]. Nevertheless, establishment of in-vivo neutralizing potency of anti-HRV-3IgY against multiple HRV serotypes would greatly simplify the comercial produc- 
tion of rotavirus specific IgY.

\section{Conclusion}

In conclusion, immunization of SPF hens with different serotypes of HRVs yielded high titered anti-HRVIgYs that displayed multiserotypic neutralizing activity invitro. The post rotavirus exposure administration of antiHRV-3IgY in mice of the present study did demonstrate the negative effect on virus replication in the gut and intestinal pathology, thereby influencing the main outcome of disease i.e. severity and duration of diarrhea in the animals. On the other hand pre exposure administration of anti-HRV-3IgY presented an ideal situation, wherein IgY imparted immediate effect implying better protection from the disease. Thus, the findings ascertain that orally supplied anti-HRVIgY decreases morbidity and disease incidences in mice infected with human rotavirus. Such preparations need to be explored as oral immunotherapy in human to reduce the rotavirus disease burden. However, implementation of this approach would require development of a formulation containing anti-HRVIgYs and its clinical trial in different settings of the rotavirus endemic region.

\section{Acknowledgements}

Authors thank Dr. A. C. Mishra, Director, NIV, Pune, India for all support. M. B., a Ph. D. scholar was supported by Indian Council of Medical Research and Dr. B V Rao Foundation, Pune. Authors gratefully acknowledge Dr. Vinayak V Limaye and Dr. Prasanth Lumpatki for their assistance during the study.

\section{REFERENCES}

[1] U. D. Parashar, C. J. Gibson, J. S. Bresee and R. I. Glass, "Rotavirus and Severe Childhood Diarrhea," Emerging Infectious Disease, Vol. 12, No. 2, 2006, pp. 304-306. doi:10.3201/eid1202.050006

[2] C. M. Zimmerman, J. S. Bresee, U. D. Parashar, T. L. Riggs, R. C. Holman and R. I. Glass, "Cost of DiarrheaAssociated Hospitalizations and Outpatient Visits in an Insured Population of Young Children in the United States," Pediatric Infectious Disease Journal, Vol. 20, No. 1, 2001, pp. 14-19. doi:10.1097/00006454-200101000-00004

[3] Y. L. Chun, L. L. Tsai, H. F. Yin, Y. W. Chung, H. H. Yu, L. H. Che, Y. C. Luan, Y. L. Chin and M. H. Li, "Disease Burden and Related Medical Costs of Rotavirus Infection in Taiwan," BMC Infectious Diseases, Vol. 6, 2006, pp. 176-184. doi:10.1186/1471-2334-6-176

[4] J. E. Tate, S. D. Chitambar, D. H. Esposito, R. Sarkar, B. Gladstone, S. Ramani, M. V. Raghava, T. V. Sowmyanarayanan, S. Gandhe, R. Arora, U. D Parashar and G. Kang, "Disease and Economic Burden of Rotavirus Diarrhoea in
India," Vaccine, Vol. 27, No. S5, 2009, pp. F18-F24. doi:10.1016/j.vaccine.2009.08.098

[5] M. Pathak and K. Haque, "Oral Immunoglobulin for the Prevention of Rotavirus Infection in Low Birth Weight Infants," Cochrane Database System of Review, Vol. 3, 2003, Article ID: CD003740. doi:10.1002/14651858.CD003740

[6] A. Z. Kapikian, L. Simonsen, T. Vesikari, Y. Hoshino, D. M. Morens, R. M. Chanock, J. R. La Montagne and B. R. Murphy, "A Hexavalent Human Rotavirus-Bovine Rotavirus (UK) Reassortant Vaccine Designed for Use in Developing Countries and Delivered in a Schedule with the Potential to Eliminate the Risk of Intussusceptions," Journal of Infectious Diseases, Vol. 192, No. S1, 2005, pp. S22-S29. doi: $10.1086 / 431510$

[7] N. Pant, A. Hultberg, Y. Zhao, L. Svensson, Q. Pan-Hammarstrom, K. Johansen, P. H. Pouwels, F. M. Ruggeri, P. Hermans, L. Frenken, T. Boren, H. Marcotte and L. Hammarstrom, "Lactobacilli Expressing Variable Domain of Llama Heavy Chain Antibody Fragments (Lactobodies) Confer Protection against Rotavirus Induced Diarrhea," Journal of Infectious Diseases, Vol. 194, No. 11, 2006, pp. 1580-1588. doi:10.1086/508747

[8] P. H. Dennehy, "Rotavirus Vaccines: An Overview," Clinical Microbiology Review, Vol. 21, No. 1, 2008, pp. 198208. doi:10.1128/CMR.00029-07

[9] G. E. Armah, S. O. Sow, R. F. Breiman, M. J. Dallas, M. D. Tapia, D. R. Feikin, F. N. Binka, A. D. Steele, K. F. Laserson, N. A. Ansah, M. M. Levine, K. Lewis, M. L. Coia, M. Attah-Poku, J. Ojwando, S. B. Rivers, J. C. Victor, G. Nyambane, A. Hodgson, F. Schödel, M. Ciarlet and K. M. Neuzil, "Efficacy of Pentavalent Rotavirus Vaccine against Severe Rotavirus Gastroenteritis in Infants in Developing Countries in Sub-Saharan Africa: A Randomised, Double-Blind, Placebo-Controlled Trial," Lancet, Vol. 376, No. 9741, 2010, pp. 606-614. doi:10.1016/S0140-6736(10)60889-6

[10] K. Zaman, D. A. Dang, J. C. Victor, S. Shin, M. Yunus, M. J. Dallas, G. Podder, D. T. Vu, T. P. Le, S. P. Luby, H. T. Le, M. L. Coia, K. Lewis, S. B. Rivers, D. A. Sack, F. Schödel, A. D. Steele, K. M. Neuzil and M. Ciarlet, "Efficacy of Pentavalent Rotavirus Vaccine against Severe Rotavirus Gastroenteritis in Infants in Developing Countries in Asia: A Randomised, Double-Blind, PlaceboControlled Trial," Lancet, Vol. 376, No. 9741, 2010, pp. 615-623. doi:10.1016/S0140-6736(10)60755-6

[11] D. H. Esposito, J. E. Tate, G. Kang and U. D. Parashar, "Projected Impact and Cost-Effectiveness of a Rotavirus Vaccination Program in India, 2008," Clinical Infectious Diseases, Vol. 52, No. 2, 2011, pp. 171-177. doi:10.1093/cid/ciq094

[12] K. Y. Green and A. Z. Kapikian, "Identification of VP7 Epitopes Associated with Protection against Human Rotavirus Illness or Shedding in Volunteers," Journal of Virology, Vol. 66, No. 1, 1992, pp. 548-553.

[13] S. M. Matsui, P. A. Offit, P. T. Vo, E. R. Mackow, D. A. Benfield, R. D. Shaw, L. Padilla-Noriega and H. B. Greenberg, "Passive Protection against Rotavirus-Induced Diarrhea by Monoclonal Antibodies to the Heterotypic Neu- 
tralization Domain of VP7 and the VP8 Fragment of VP4," Journal of Clinical Microbiology, Vol. 27, No. 4, 1989, pp. 780-782.

[14] P. A. Offit, H. F. Clark, G. Blavat and H. B. Greenberg, "Reassortant Rotaviruses Containing Structural Proteins VP3 and VP7 from Different Parents Induce Antibodies Protective against Each Parental Serotype," Journal of Virology, Vol. 60, No. 2, 1986, pp. 491-496.

[15] P. A. Offit, R. D. Shaw and H. B. Greenberg, "Passive Protection against Rotavirus-Induced Diarrhea by Monoclonal Antibodies to Surface Proteins of VP3 and VP7," Journal of Virology, Vol. 58, No. 2, 1986, pp. 700-703.

[16] F. M. Ruggeri, K. Johansen, G. Basile, J. P. Kraehenbuhl and L. Svensson, "Antirotavirus Immunoglobulin a Neutralizes Virus in Vitro after Transcytosis through Epithelial Cells and Protects Infant Mice from Diarrhea," Journal of Virology, Vol. 72, No. 4, 1998, pp. 2708-2714.

[17] L. E. Westerman, H. M. McClure, B. Jiang, J. W. Almond and R. I. Glass, "Serum IgG Mediates Mucosal Immunity against Rotavirus Infection," Proceedings of the National Academy of Sciences of the United States of America, Vol. 102, No. 20, 2005, pp. 7268-7273. doi:10.1073/pnas.0502437102

[18] L. Hammarström, "Passive Immunity against Rotavirus in Infants," Acta Paediatrica, Vol. 88, No. 430, 1999, pp. 127-132.

[19] G. W. Warr, K. E. Magor and D. A. Higgins, "IgY: Clues to the Origins of Modern Antibodies," Immunology Today, Vol. 16, No. 8, 1995, pp. 392-398. doi:10.1016/0167-5699(95)80008-5

[20] A. Larsson and J. Sjöquist, "Chicken IgY: Utilizing the Evolutionary Difference," Comparative Immunology Microbiology Infectious Diseases, Vol. 13, No. 4, 1990, pp. 199-201. doi:10.1016/0147-9571(90)90088-B

[21] M. Kuroki, Y. Ikemori, H. Yokoyama, R. C. Peralta, F. C. Icatlo Jr. and Y. Kodama, "Passive Protection against Bovine Rotavirus-Induced Diarrhea in Murine Model by Specific Immunoglobulins from Chicken Egg Yolk," Veterinary Microbiololgy, Vol. 37, 1993, pp. 135-146. doi:10.1016/0378-1135(93)90188-D

[22] T. Ebina, "Prophylaxis of Rotavirus Gastroenteritis Using Immunoglobulin," Archives of Virology, Vol. 12, 1996, pp. 217-223.

[23] S. A. Sarker, N. Pant, L. R. Juneja and L. Hammarström, "Successful Treatment of Rotavirus-Induced Diarrhoea in Suckling Mice with Egg Yolk Immunoglobulin," Journal of Health and Population Nutrition, Vol. 25, No. 4, 2007, pp. 465-468.

[24] S. D. Kelkar, V. S. Bhide, S. S. Ranshing and S. S. Bedekar, "Rapid ELISA for the Diagnosis of Rotavirus," Indian Journal of Medical Research, Vol. 119, No. 2, 2004, pp. 60-65.

[25] S. D. Kelkar, P. G. Ray and S. S. Bedekar, "Assay of Neutralizing Antibodies to Animal Rotavirus Strains and Human Rotavirus Serotype G8 by Modified Method in the Resident of Pune, India," Journal of Diarrhoeal Disease Research, Vol. 14, No. 2, 1996, pp. 101-106.
[26] M. S. Poruchynsky and P. H. Atkinson, "Rotavirus Protein Rearrangements in Purified Membrane-Enveloped Intermediate Particles," Journal of Virology, Vol. 65, No. 9, 1991, pp. 4720-4727.

[27] O. H. Lowry, N. J. Rosebrough, A. L. Farr and R. J. Randall, "Protein Measurement with the Folin Phenol Reagent," The Journal of Biological Chemistry, Vol. 193, No. 1, 1951, pp. 265-275.

[28] A. Polson, T. Coetzer, J. Kruger, E. von Maltzahn and K. J. van der Merwe, "Improvements in the Isolation of IgY from the Yolks of Eggs Laid by Immunized Hens," Immunological Investigations, Vol. 14, No. 4, 1985, pp. 323327.

[29] R. H.Yolken, F. Leister, S. B. Wee, R. Miskuff and S. Vonderfecht, “Antibodies to Rotavirusesin Chicken's Eggs: A Potential Source of Antiviral Immunoglobulins Suitable for Human Consumption," Pediatrics, Vol. 81, No. 2, 1988, pp. 291-295.

[30] P. G. Ray and S. D. Kelkar, "Prevalence of Neutralizing Antibodies against Different Rotavirus Serotypes in Children with Severe Rotavirus-Induced Diarrhea and Their Mothers," Clinical and Diagnostic Laboratory Immunology, Vol. 11, No. 1, 2004, pp. 186-194. doi:10.1128/CDLI.11.1.186-194.2004

[31] D. Katz, E. Freeman, M. Davidson, M. Abramson and P. Fuchs, "Detection of Anti-Rabies Neutralizing Antibodies in Humans and Cattle by a Combined Tissue Culture and Enzyme Linked Immunoassay," Israel Journal of Veterinary Medicine, Vol. 53, No. 4, 1998, pp. 132-142.

[32] M. Buragohain, G. S. Dhale, C. G. Raut, G. Kang and S. D. Chitambar, "Analyses of Clinical, Pathological and Virological Features of Human Rotavirus Strain, YO Induced Gastroenteritis in Infant BALB/c Mice," Microbes and Infection, Vol. 13, No. 4, 2011, pp. 331-338. doi:10.1016/j.micinf.2010.12.001

[33] K. Takahashi, K. Ohashi, Y. Abe, S. Mori, K. Taniguchi, T. Ebina, O. Nakagomi, M. Terada and S. Shigeta, "Protective Efficacy of a Sulfated Sialyl Lipid (NMSO3) against Human Rotavirus-Induced Diarrhea in a Mouse Model," Antimicrobial Agents and Chemotherapy, Vol. 46, No. 2, 2002, pp. 420-424.

doi:10.1128/AAC.46.2.420-424.2002

[34] G. Kang, M. Iturriza-Gomara, J. G. Wheeler, P. Crystal, B. Monica, S. Ramani, B. Primrose, P. D. Moses, C. I. Gallimore, D. W. Brown and J. Gray, "Quantitation of Group A Rotavirus by Real-Time Reverse-TranscriptionPolymerase Chain Reaction: Correlation with Clinical Severity in Children in South India," Journal of Medical Virology, Vol. 73, No. 1, 2004, pp. 118-122. doi:10.1002/jmv.20053

[35] N. Pant, H. Marcotte, H. Brüssow, L. Svensson and L. Hammarström, "Effective Prophylaxis against Rotavirus Diarrhea Using a Combination of Lactobacillus rhamnosus GG and Antibodies," BMC Microbiology, Vol. 7, 2007, p. 86. doi:10.1186/1471-2180-7-86

[36] G. Phillips, B. Lopman, C. Tam, M. Iturriza-Gomara, D. Brown and J. Gray, "Diagnosing Rotavirus a Associated IID: Using ELISA to Identify a Cut-Off for Real Time 
RT-PCR," Journal of Clinical Virology, Vol. 44, No. 3, 2009, pp. 242-245. doi:10.1016/j.jcv.2008.12.001

[37] L. G. Luna, "Manual of Histological Staining Methods of the Armed Forces Institute of Pathology," 3rd Edition, McGraw Hill, New York, 1968.

[38] R. A. Fisher, "Statistical Methods for Research Workers," Oliver and Boyd, Edinburgh, 1954.

[39] Kruskal and Wallis, "Use of Ranks in One-Criterion Variance Analysis," Journal of the American Statistical Association, Vol. 47, No. 260, 1952, pp. 583-621. doi: $10.2307 / 2280779$

[40] F. Wilcoxon, "Individual Comparisons by Ranking Methods," Biometrics Bulletin, Vol. 1, No. 6, 1945, pp. 80-83. doi: $10.2307 / 3001968$

[41] J. A. Boshuizen, J. H. Reimerink, A. M. Korteland-van Male, V. J. van Ham, M. P. Koopmans, H. A. Büller, J. Dekker and A. W. Einerhand, "Changes in Small Intestinal Homeostasis, Morphology, and Gene Expression during Rotavirus Infection of Infant Mice," Journal of Virology, Vol. 77, No. 24, 2003, pp. 13005-13016. doi:10.1128/JVI.77.24.13005-13016.2003

[42] J. Kovacs Nolan and Y. Mine, "Avian Egg Antibodies: Basic and Potential Applications," Avian and Poultry Biology Reviews, Vol. 15, No. 1, 2004, pp. 25-46. doi:10.1128/JVI.77.24.13005-13016.2003

[43] R. Schade and A. Hlinak, "Egg Yolk Antibodies, State of the Art and Future Prospects," Alternatives to Animal Experimentation, Vol. 13, No. 5, 1996, pp. 5-9.

[44] R. Chalghoumi, Y. Beckers, D. Portetelle and A. Théwis, "Hen Egg Yolk Antibodies (IgY), Production and Use for Passive Immunization against Bacterial Enteric Infections in Chicken: A Review," Biotechnology, Agronomy, Society and Environment, Vol. 13, No. 2, 2009, pp. 295-308.

[45] P. S. Paul and Y. S. Lyoo, "Immunogens of Rotaviruses," Veterinary Microbiology, Vol. 37, No. 3-4, 1993, pp. 299317. doi:10.1016/0378-1135(93)90031-2

[46] M. E. Cook and D. L. Trott, "IgY-Immune Component of Eggs as a Source of Passive Immunity for Animals and Humans," World's Poultry Science Journal, Vol. 66, No. 2, 2010, pp. 215-226. doi:10.1017/S0043933910000279

[47] T. Ebina, K. Tsukada, K. Umezu, M. Nose, K. Tsuda, H. Hatta, M. Kim and T. Yamamoto, "Gastroenteritis in Suckling Mice Caused by Human Rotavirus Can Be Prevented with Egg Yolk Immunoglobulin (IgY) and Treated with a Protein-Bound Polysaccharide Preparation (PSK)," Microbiology and Immunology, Vol. 34, No. 7, 1990, pp. 617-629.

[48] R. R. Marquardt, L. Z. Jin, J. W. Kim, L. Fang, A. A. Frohlich and S. K. Baidoo, "Passive Protective Effect of
Egg-Yolk Antibodies against Enterotoxigenic Escherichia coli K88+ Infection in Neonatal and Early-Weaned Piglets," FEMS Immunology and Medical Microbioogyl, Vol. 23, No. 4, 1999, pp. 283-288.

[49] S. Rahimi, Z. M. Shiraz, T. Z. Salehi, M. A. K. Torshizi and J. L. Grimes, "Prevention of Salmonella Infection in Poultry by Specific Egg-Derived Antibody," International Journal of Poultry Science, Vol. 6, No. 4, 2007, pp. 230235. doi:10.3923/ijps.2007.230.235

[50] P. A. Offit and H. F. Clark, "Maternal Antibody-Mediated Protection against Gastroenteritis Due to Rotavirus in Newborn Mice Is Dependent on Both Serotype and Titer of Antibody," Journal of Infectious Diseases, Vol. 152 , No. 6,1985 , pp. $1152-1158$ doi:10.1093/infdis/152.6.1152

[51] R. J. Gorrell and R. F. Bishop, "Homotypic and Heterotypic Serum Neutralizing Antibody Response to Rotavirus Proteins Following Natural Primary Infection and Reinfection in Children," Journal of Medical Virology, Vol. 57, No. 2, 1999, pp. 204-211. doi:10.1002/(SICI)1096-9071(199902)57:2<204::AID-J MV20>3.0.CO;2-Y

[52] J. G. Lecce, H. L. Leary Jr., D. A. Clarke and R. P. Batema, "Protection of Agammaglobulinemic Piglets from Porcine Rotavirus Infection by Antibody against Simian Rotavirus SA-11," Journal of Clinical Microbiology, Vol. 29, 1991, pp. 1382-1386.

[53] G. Menchaca, L. P. Noriega, M. M. Toss, J. F. Contreras, F. I. Puerto, H. Guiscafré, F. Mota, I. Herrera, R. Cedillo, O. Muñoz, R. Ward, Y. Hoshino, S. López and C. F. Arias, "Serotype Specificity of the Neutralizing-Antibody Response Induced by the Individual Surface Proteins of Rotavirus in Natural Infections of Young Children," Clinical and Diagnostic Laboratory Immunology, Vol. 5, No. 3, 1998, pp. 328-334.

[54] S. E. Crawford, M. K. Estes, M. Ciarlet, C. Barone, C. M. O’Neal, J. Cohen and M. E. Conner, "Heterotypic Protection and Induction of a Broad Heterotypic Neutralization Response by Rotavirus-Like Particles," Journal of Virology, Vol. 73, No. 6, 1999, pp. 4813-4822.

[55] D. Y. Graham, G. R. Dufour and M. K. Estes, "Minimal Infective Dose of Rotavirus," Archives of Virology, Vol. 92, No. 3-4, 1987, pp. 261-271. doi:10.1007/BF01317483

[56] L. M. Bell, H. F. Clark, E. A. O’Brien, M. J. Kornstein, S. A. Plotkin and P. A. Offit, "Gastroenteritis Caused by Human Rotaviruses (Serotype Three) in a Suckling Mouse Model," Proceedings of the Society for Experimental Biology and Medicine, Vol. 184, No. 1, 1987, pp. 27-132. 